Marquette University

e-Publications@Marquette

School of Dentistry Faculty Research and

Publications

Dentistry, School of

$11-1-2015$

\title{
Biomaterial Properties of Titanium in Dentistry
}

Soni Prasad

Marquette University, soni.prasad@marquette.edu

Mark Ehrensberger

State University of New York at Buffalo

Monica Prasad Gibson

The Ohio State University

Hyeongil Kim

State University of New York at Buffalo

Edward A. Monaco, Jr.

State University of New York at Buffalo

Accepted version. Journal of Oral Biosciences, Vol. 57, No. 4 (November 2015): 192-199. DOI. (C) 2015 Elsevier. Used with permission. 


\section{Marquette University}

\section{e-Publications@Marquette}

\section{Dentistry Faculty Research and Publications/School of Dentistry}

This paper is NOT THE PUBLISHED VERSION; but the author's final, peer-reviewed manuscript. The published version may be accessed by following the link in the citation below.

Journal of Oral Biosciences, Vol. 57, No. 4 (2015): 192-199. DOI. This article is (C) Elsevier and permission has been granted for this version to appear in e-Publications@Marquette. Elsevier does not grant permission for this article to be further copied/distributed or hosted elsewhere without the express permission from Elsevier.

\section{Biomaterial Properties of Titanium in Dentistry}

\section{Soni Prasad}

School of Dentistry, Marquette University, Milwaukee WI

\section{Abstract \\ Background}

Among various dental materials and their successful restorative uses, titanium provides an excellent example of integrating science and technology involving multiple disciplines of dentistry including biomaterials, prosthodontics and surgical sciences. Titanium and its alloys have emerged as a material of choice for dental implants fulfilling all requirements biologically, chemically and mechanically. Several excellent reviews have discussed the properties of titanium and its surface characteristics that render it biocompatible. However, in most patients, titanium implants are used alongside several other metals. Presence of different metals in the same oral environment can alter the properties of titanium. Other influencing factors include intra-oral pH, salivary content, and effect of fluorides.

\section{Highlight}

This review discusses the effect of the above-mentioned conditions on the properties of titanium and its alloys. An extensive literature search encompassing the properties of titanium in an altered oral environment and its interaction with other restorative materials is presented. Specific conditions that 
could cause titanium to corrode, specifically due to interaction with other dental materials used in oral rehabilitation, as well as methods that can be employed for passivation of titanium are discussed.

\section{Conclusion}

This review presents an overview of the properties of titanium that are vital for its use in implant dentistry. From a restorative perspective, interaction between implant restoration metals, intra-oral fluorides and $\mathrm{pH}$ may cause titanium to corrode. Therefore, in order to avoid the resulting deleterious effects, an understanding of these interactions is important for long-term prognosis of implant restorations.

\section{Keywords}

Dental implant, Titanium, Titanium corrosion, Titanium alloy, Galvanic corrosion

\section{Introduction}

Commercially pure titanium (CpTi) and titanium (Ti) alloys have been used successfully in dentistry and orthopedics for many years. These materials have become the material of choice in dental implants due to favorable material characteristics and biocompatibility in the oral environment. ${ }^{1-3}$ The biomaterial properties of $\mathrm{CpTi}$ include a combination of mechanical strength, chemical stability as well as its successful integration with the surrounding bone (osseointegration). ${ }^{2,3}$ Additional advantages of using $\mathrm{CpTi}$ and/or Ti alloys in dentistry include its high strength-to-weight ratio and resistance to corrosion..$^{2,4}$ Ti has a neutral taste and is considered to be translucent to $x$-rays making diagnostic radiographs feasible in the presence of titanium castings. ${ }^{5-7} \mathrm{Ti}$ is also non-ferromagnetic and therefore, patients with titanium implants can safely undergo magnetic resonance imaging. ${ }^{8}$ Additionally, the modulus of elasticity of $\mathrm{Ti}$ is similar to that of bone, making the bone-to-implant interface closer matching than many other metals. ${ }^{9}$ Due to these properties, $\mathrm{CpTi}$ and $\mathrm{Ti}$ alloys are now extensively used to fabricate endodontic files, orthodontic wires and brackets and dental implants. ${ }^{10}$

Ti was first discovered in England by William Gregor in $1791 .{ }^{11}$ However, its use for dental implants was discovered much later by Brånemark. ${ }^{3}$ Since then tremendous amount of research has been done that has dramatically influenced the clinical treatment planning of dental implants. Several generations of titanium implants have emerged over the last few decades owing to the huge advances made in biomaterial science. ${ }^{12-16}$ Most of the body of research has been focused in developing or enhancing molecular interactions, cellular response, surface treatment and eventually improving osseointegration..$^{13-16}$ Several laboratories have done extensive surface engineering with in vitro and in vivo experiments for the development of implant surface modifications to enhance osseointegration. ${ }^{12-16}$ This has led to improved implant stability during the healing process resulting in improved clinical performance especially in challenging cases with reduced bone quantity and quality. ${ }^{17}$ These improved characteristics have proved beneficial for faster bone healing and reduced implant-loading timelines.

Several reviews have discussed the beneficial properties of titanium in dentistry. ${ }^{1,17-21}$ However, a review of the literature from a restorative perspective encompassing the behavior of titanium in an altered oral environment and its interaction with other restorative materials is lacking. Specific conditions can result in altered effect in the material properties of titanium. Use of dissimilar 
restorative metals leading to galvanic coupling could result in corrosion. ${ }^{22}$ Other changes include effect of fluoride, alteration in oral $\mathrm{pH}$ and hypersensitivity reaction to titanium. ${ }^{23,24}$ Understanding of these various interactions with titanium is crucial from a restorative and prosthodontics aspect. The purpose of this review is to provide an overview of the properties of titanium that are responsible for its beneficial characteristics specifically as related to its use in restorative implant dentistry. Specific conditions that could result in adverse effects due to interaction of titanium with other dental materials used in oral rehabilitation as well as methods that can be employed for passivation of titanium are presented.

\section{Structure}

Ti is the ninth most abundant element found in the earth's crust and needs to be extracted from mineral ores such as rutile and ilmenite. ${ }^{25}$ In 1936 with the introduction of Kroll's process for extracting $\mathrm{Ti}$, industrial use of $\mathrm{Ti}$ increased exponentially. ${ }^{26} \mathrm{Ti}$ is an allotropic element and can exist in 2 crystal orientations (Fig. 1). ${ }^{26}$ At temperatures below $882{ }^{\circ} \mathrm{C}$, pure Ti exists as a hexagonal close-packed crystal also called the alpha phase (Fig. 1). Above $882^{\circ} \mathrm{C}$, it exists as a body centered cubic crystal known as the beta phase (Fig. 1). ${ }^{5,27}$ However, through selective alloying with other elements it is possible to create $\mathrm{Ti}$ alloys with stable alpha phase, beta phase or alpha+beta phase at room temperature. ${ }^{28}$ Elements like aluminum, carbon, oxygen and nitrogen stabilize the alpha phase of Ti and elements like manganese, chromium, iron, and vanadium stabilize the beta phase. ${ }^{5,29}$ The Ti implants used in dentistry are most commonly composed of commercially pure titanium (cpTi) or titanium-6aluminum4vanadium (Ti-6Al-4V). ${ }^{29}$ The cpTi is a single (alpha) phase crystal at body temperature whereas the $\mathrm{Ti}-6 \mathrm{Al}-4 \mathrm{~V}$ is an alpha+beta phase alloy. ${ }^{5,28}$

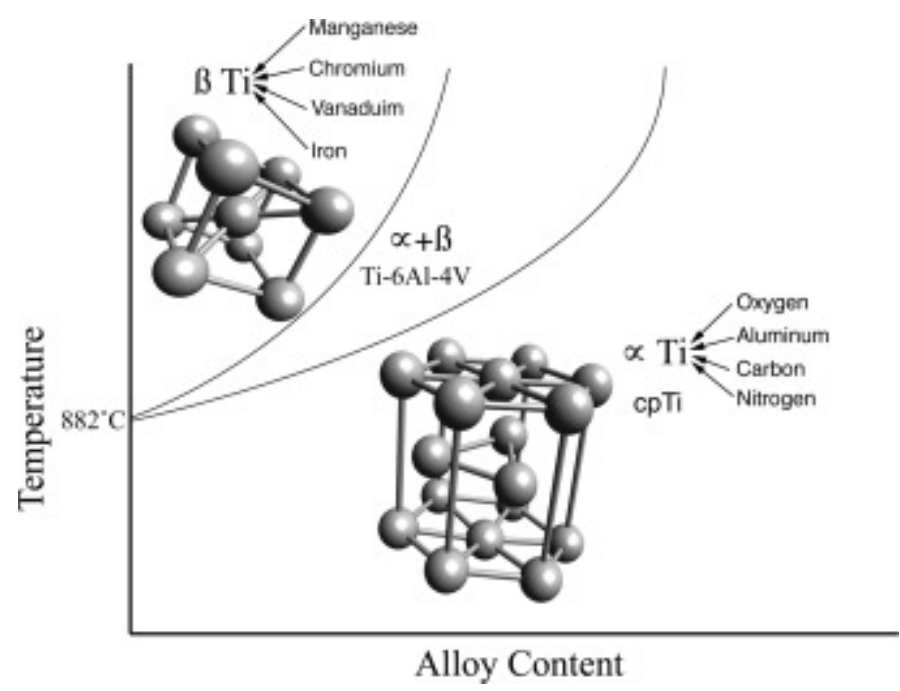

Fig. 1. Crystalline structure of Ti. Below $882^{\circ} \mathrm{C} \mathrm{Ti} \mathrm{exists} \mathrm{in} \mathrm{hexagonal} \mathrm{alpha}(\alpha)$ phase. Elements like Al, $\mathrm{C}, \mathrm{O}$ and $\mathrm{N}$ stabilize the alpha phase. At a temperature above $882^{\circ} \mathrm{C}$ Ti exists as centered cubic crystal $(\beta)$ phase. Elements like $\mathrm{Mn}, \mathrm{Cr}$, Fe and $\mathrm{Vn}$ stabilize the beta phase. Selective alloying helps create stable alpha+beta phase.

$\mathrm{Ti}$ is highly reactive and belongs to the transition group of elements in the periodic table. The atomic number and atomic mass of $\mathrm{Ti}$ is 22 and 47.88 respectively. The electrons in $\mathrm{Ti}$ are arranged around its nucleus in 4 energy levels having 2, 8, 10 and 2 electrons respectively (Fig. 2). ${ }^{30}$ Each energy level is 
further divided into energy sublevels of $s, p, d$ and $f$. The electronic configuration of Ti is $1 s^{2} 2 s^{2} p^{6}$ $3 s^{2} p^{6} d^{2} 4 s^{2}$ with lightly held valence electrons in $3 d^{2} 4 s^{2}$ energy sublevels (Fig. 2$)^{26}$ These lightly held valence electrons are responsible for making titanium highly reactive. ${ }^{25,29,31}$

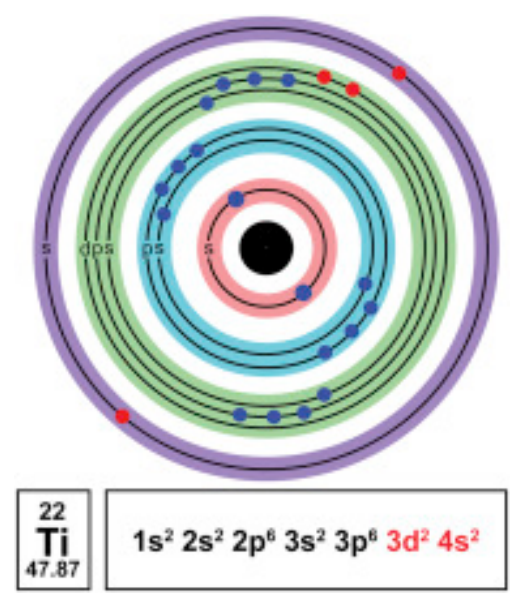

Fig. 2. Electron valence structure of Ti. Electron in Ti arranged in 4 energy levels. Each energy level has electrons arranged on $s, p, d$ and f subshells. 2 Electrons in energy level 3 ( $d$ subshell) and 2 electrons in energy level 4 (s subshells) are responsible for the highly reactive state of Ti.

\section{Titanium passivation}

Titanium has a standard reduction potential of $-1.6 \mathrm{~V} .{ }^{29}$ This indicates that $\mathrm{Ti}$ is a very reactive metal that wants to undergo oxidation (i.e. Ti wants to corrode). However, when exposed to water or air, pure metallic Ti spontaneously reacts to form a thin oxide layer at the surface. ${ }^{29}$ Oxygen with a valency of only 2 electrons is relatively electronegative and readily binds with the lightly held valence electrons of titanium to form a tenacious oxide layer (i․ 3 ). ${ }^{25,29}$

$$
\begin{array}{ll}
\mathrm{Ti}+\mathrm{O}_{2} \rightarrow \mathrm{TiO}_{2} & \Delta \mathrm{G}=-203.8 \mathrm{kcal} / \mathrm{mol} \\
\mathrm{Ti}+2 \mathrm{H}_{2} \mathrm{O} \rightarrow \mathrm{TiO}_{2}+4 \mathrm{H}^{+}+4 \mathrm{e}^{-} & \Delta \mathrm{G}=-82.29 \mathrm{kcal} / \mathrm{mol}
\end{array}
$$

Fig. 3. Oxide layer formation. Ti spontaneously reacts with air and water to form a thin layer of oxide $\left(\mathrm{TiO}_{2}\right)$ at the surface

Cabrera and Mott $^{29}$ and Fehlner and Mott ${ }^{32}$ have described a high field mechanism for oxide film formation and growth. According to this theory the oxide layer formation starts with adsorption of oxygen on pure titanium surfaces to create a monolayer of oxide. Subsequent electron tunneling from the titanium, through the oxide, to other adsorbed oxygen creates oxygen ions, which act as an electron trap at the surface. An increase in potential drop is observed as the traps accumulate. This, in turn, establishes an electric field across the film which acts to lower the activation energy for ion transport through the film. For oxide formation to continue, the titanium and the oxygen need to be brought into contact. The oxide film formed on titanium is classified as an N-type semiconductor. This means that anion mobility (oxygen ions) is the dominant mechanism of ion transport. ${ }^{31,32}$ Therefore, the oxygen ions move through the oxide film to the titanium surface to form new oxide layer. This mechanism of formation is referred to as growth at constant field. ${ }^{31}$ Since the mobile ions and the 
field-creating ions are the same, the rate at which new field-creating anions are formed at the surface must balance the rate of anion transport. In this model it is further assumed that as the oxide film thickens the activation energy for ion transport increases and eventually limits further oxide formation. If the potential drop increases across the film (Ti anodic polarization), the electric field is increased and this provides a means to continue oxide growth. This oxide thickening process is known as anodization and the oxide film on Ti will increase approximately $2 \mathrm{~nm} / \mathrm{V} .{ }^{31}$ Alternatively, cathodic potentials applied to $\mathrm{Ti}$ can reduce the valance state of the $\mathrm{Ti}$ ions within the oxide film, increasing the oxide solubility and thinning through reductive dissolution. ${ }^{30}$

The Pourbaix ( $\mathrm{pH}$-potential) diagram for titanium shown in Fig. 4 was generated base upon thermodynamic predictions of the reactions and reaction products present at equilibrium. ${ }^{33-37}$ The different regions of the diagram indicate the conditions that favor corrosion, passivation, or immunity. The corrosion region (shaded area in Fig. 4) occurs where soluble ions of titanium are stable. In the immune region of the diagram only the reduced form of the metal is stable and therefore corrosion is thermodynamically impossible. The passive region indicates were an oxide is stable. ${ }^{33-36}$ This illustrates that an oxide film ( $\mathrm{TiO}, \mathrm{Ti}_{2} \mathrm{O}_{3}, \mathrm{TiO}_{2}$ ) is stable over a wide range of $\mathrm{pH}$ and potentials (Fig. 4).

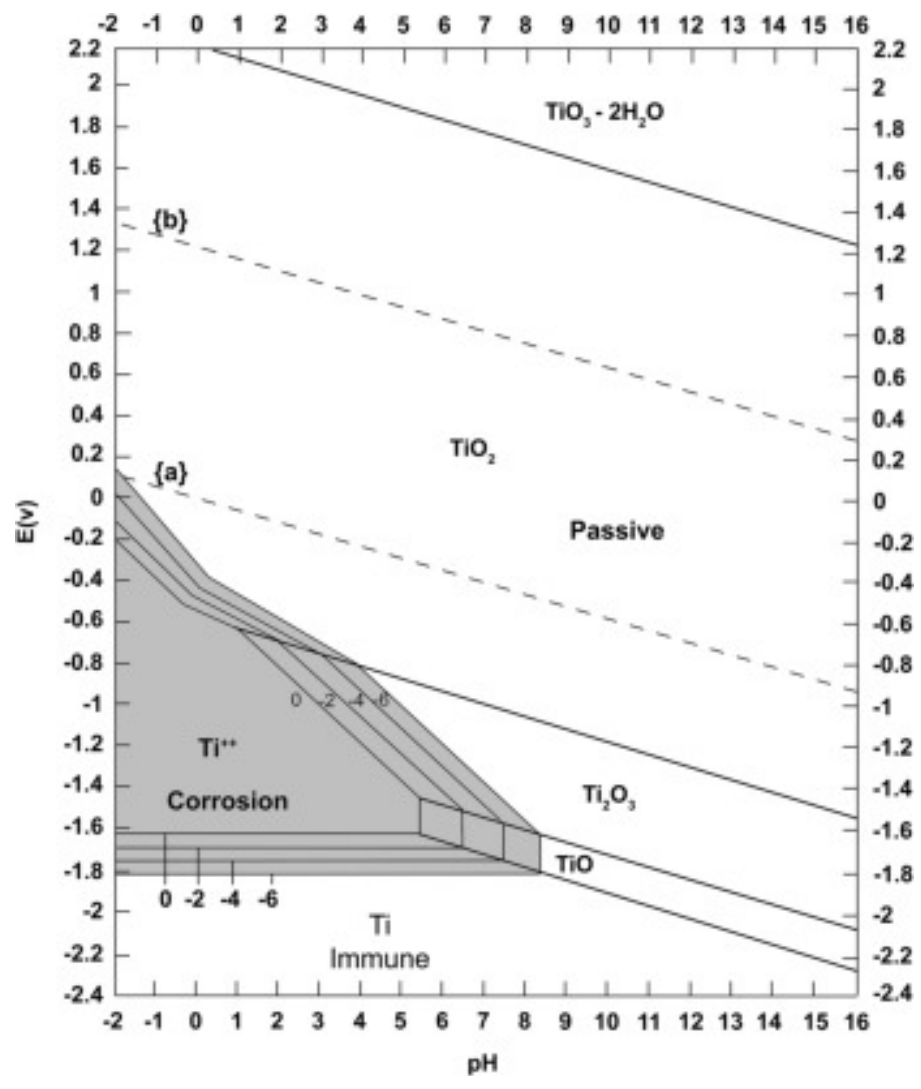

Fig. 4. Pourbiax diagram for Ti in water. Diagram showing thermodynamic predictions of the reactions and reaction products of $\mathrm{Ti}$ in the presence of water at equilibrium. The different regions of the diagram indicate the conditions that favor corrosion, passivation, or immunity, thus illustrating that an oxide film on $\mathrm{Ti}$ surface $\left(\mathrm{TiO}, \mathrm{Ti}_{2} \mathrm{O}_{3}, \mathrm{TiO}_{2}\right)$ is stable over a wide range of $\mathrm{pH}$ and potentials. 
(Reused from Corrosion Science, vol. 53, MJ Munoz-Portero et.al, Pourbaix diagrams for titanium in concentrated aqueous lithium bromide solutions at $25^{\circ} \mathrm{C}$, p. 1443 , Copyright 2011 , with permission from Elsevier.)

The formation of this oxide film is referred to as passivation because the highly dynamic oxide layer subsequently acts as a barrier to protect the underlying metallic Ti from further exposure and chemical reaction (corrosion). Therefore, despite being an active metal, titanium exhibits high corrosion resistance due to the presence of the oxide film. ${ }^{34-36}$

\section{Titanium biocompatibility}

Biocompatibility is defined as the state of mutual coexistence between the biomaterials and the physiological environment without any undesirable effect. ${ }^{38}$ To understand biocompatibility, it is important to understand the interaction between the biomaterial and the biological system. These interactions are usually seen on a molecular level in an interface zone of about $1 \mathrm{~nm} .{ }^{38}$ Titanium application in implant dentistry is due to its ability to osseointegrate with bone which was discovered accidently by the landmark work of Brånemark. ${ }^{3}$ He later coined the term osseointegration to describe the "direct structural and functional connection between living, ordered bone and the surface of a load carrying implant. ${ }^{3}$ In the Glossary of Prosthodontic terms, osseointegration is defined as the apparent direct attachment or connection of osseous tissue to an inert, alloplastic material without intervening connective tissue. ${ }^{39}$

Since its introduction, the concept of osseointegration has received much attention in the literature. There is a strong interest in identifying the surface properties of the titanium such as topography, chemistry, energetics and electrochemical impedance that define this advantageous biological response. This includes but is not restricted to adsorption of proteins with proper conformation and function, limiting deleterious foreign body reaction, and enhancing the recruitment, attachment, and proliferation of precursor cells that differentiate into mature, mineralizing osteoblasts, etc. Although titanium alloys are exceptionally corrosion-resistant because of the stability of the $\mathrm{Ti}$ oxide $\left(\mathrm{TiO}_{2}\right)$ layer, they are not inert to corrosive attack. Similar to other base metals, titanium can become susceptible to corrosion when the stable oxide layer is disrupted and is unable to repair. ${ }^{40,41}$ The following sections emphasize the process of Ti corrosion and factors accelerating it in oral environment.

\section{Titanium corrosion}

The term corrosion is defined as the chemical or the electrochemical reaction between a material, usually a metal, and its environment that produces a deterioration of the metal itself and its properties. ${ }^{33}$ There are several types of corrosion observed in dental materials. These include galvanic, fretting, crevice corrosion, environmentally induced cracking (EIC) and microbiology induced corrosion. ${ }^{33,35,36,38,41}$ Galvanic corrosion occurs when there is a direct contact of two dissimilar metals in an electrolytic solution. ${ }^{42-44}$ Fretting corrosion is caused by friction leading to mechanical wear and damage to the passivation layer on the Ti surface. ${ }^{45}$ Fretting between dental implants and bone due to cyclic loading experienced during chewing has been suggested as a cause of Ti corrosion and release of metal debris into tissue. ${ }^{45,46}$ This release of ion and metal debris has been associated with cytotoxicity, inhibition of cell differentiation, phagocytosis of Ti particles by macrophages, inflammation, and neoplastic changes. ${ }^{47-49}$ In addition, the fretting associated cathodic shift in the open circuit potential 
of cpTi implants $s^{50-53}$ alters the electrochemical properties of the cpTi interface ${ }^{54,55}$ and has been associated with reduced biocompatibility. ${ }^{51,56-58}$

Crevice corrosion is a localized corrosion due to a geometric confinement in the design of the device. Crevice corrosion occurs between two close surfaces or in constricted places where oxygen exchange is not available. ${ }^{45,59}$ The reduction in $\mathrm{pH}$ and increase in the concentration of chlorine ions are two essential factors in the initiation and propagation of the crevice corrosion phenomenon. When the acidity of the environment increases with time the passive layer of the alloy dissolves and this accelerates the local corrosion process. ${ }^{59}$ While pitting corrosion is not likely to occur on Ti surfaces, crevice corrosion has been reported. ${ }^{40,45,59}$ Environmentally induced cracking (EIC) is the brittle mechanical failure of metallic devices under stress levels significantly lower than their ultimate tensile strength. ${ }^{60}$ This usually occurs in susceptible materials in a corrosive environment under continuous loading.

\section{Effect of dissimilar metal on titanium corrosion}

It is well known that the breakdown potential of titanium alloys in saline solutions is very high when compared to cobalt-chromium and stainless steel alloys. Therefore, the likelihood of galvanic coupling between titanium implants and restorations of non-precious metals in an oral environment is a potential concern. Such a galvanic couple may accelerate the corrosion of the other metal, leading to increased metal ion release. ${ }^{9}$ Galvanic corrosion is the most common form of corrosion seen with titanium implants and is accelerated due to an electrical contact with a more noble or nonmetallic conductor in a corrosive environment. ${ }^{22}$

When dental prostheses made of 2 or more dissimilar alloys come in contact in oral environment, the difference between their electric potential results in flow of electric current between them. ${ }^{61} \mathrm{An}$ oxidation-reduction reaction is established with oxidation occurring at anode (more reactive metal) and reduction at the cathode. A galvanic cell is formed intra-orally and the galvanic current results in acceleration of corrosion of less noble metal ( $\underline{\text { Fig. } 5}$ ). The galvanic current passes not only through the dissimilar metal present in the oral cavity but also through tissues and bone resulting in discomfort to the patient. ${ }^{22,61}$ In the presence of noble alloys, Ti acts as an anode showing virtually no interaction. ${ }^{62}$ Therefore, materials used as superstructures over Ti implants should be carefully chosen. Galvanic and pitting corrosion is responsible for the electrochemical process occurring at the implant and implant superstructure junction. ${ }^{63}$ In the presence of iron and nickel based alloys titanium acts as cathode and establishes a galvanic circuit which accelerates the corrosion of these alloys. ${ }^{22,64}$ 


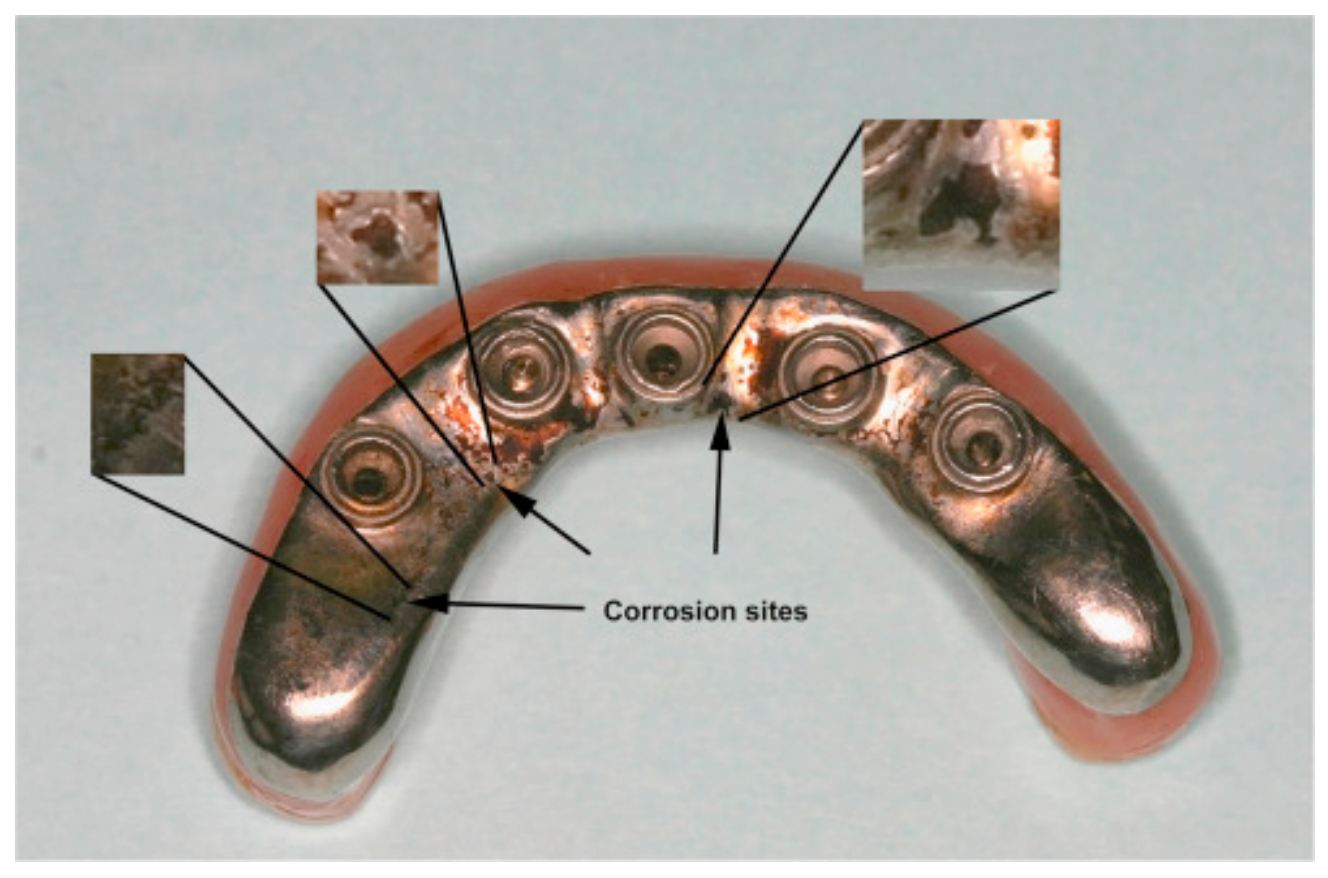

Fig. 5. Ti induced corrosion in implant superstructure. Arrow indicates areas of corrosion of implant superstructure. Galvanic coupling between Ti implants and restorations of non-precious metals in an oral environment results in corrosion of the non-precious (less Nobel) alloy.

Studies by Venugopalan et al. ${ }^{65}$ investigated galvanic corrosion properties of restorative materials when coupled with titanium. Artificial saliva solution was used as an electrolyte medium for establishing a galvanic cell. It was found that noble alloys like gold, silver and palladium when coupled to titanium were least susceptible to galvanic corrosion. On the other hand, $\mathrm{Co}-\mathrm{Cr}-\mathrm{Mo}, \mathrm{Ni}-\mathrm{Cr}$ and $\mathrm{Fe}-$ based alloys when coupled to titanium were found to be moderately susceptible to galvanic corrosion due to mechanical-electrochemical interaction. $\mathrm{Ni}-\mathrm{Cr}-\mathrm{Be}$ alloy coupled to titanium was found to be highly susceptible to galvanic corrosion. The absence of galvanic action occurring between titanium and both palladium and gold was due to the fact that they had similar electrochemical potential values as titanium. ${ }^{65}$ Therefore, in order for the simultaneous existence of two dissimilar alloys to be compatible in an oral environment, the difference in their open circuit potential and the current density should be as small as possible. ${ }^{65}$

In a separate study by Arslan et al. ${ }^{66}$ corrosion behavior of titanium alloy (Ti-6Al-4V) with gold (Au), chromium-nickel ( $\mathrm{CrNi}$ ) and cobalt-chromium ( $\mathrm{CoCr}$ ) in ringer's solution was investigated. They too showed that titanium when coupled with gold was least susceptible to the galvanic corrosion as compared to titanium coupled with either $\mathrm{CoCr}$ or CrNi alloys.

Dental amalgam is one of the most common choices of direct restorative material for intra-oral use. ${ }^{62,67}$ In the past, mercury toxicity concerns have resulted in an alternative use of mercury free, gallium-based alloy for direct filling material. Although these materials have a passivating film, it is less protective than the one on titanium. When Ti comes in contact with these alloys, it behaves as a noble metal, causing corrosion of amalgam or gallium. ${ }^{61}$ Studies show that the galvanic interaction between titanium and direct filling copper/gallium alloy was minimal. But due to poor corrosion resistance of gallium alloys even small increase in corrosion due to galvanic interaction had a potential of making the corrosion problem severe. ${ }^{61}$ Interaction between titanium and dental amalgam were also reported by 
Ravnholt. ${ }^{62}$ In their in vitro study they used $1 \%$ sodium chloride to simulate oral environment and found that titanium behaves as a cathode with a high current density of $18 \mu \mathrm{A} / \mathrm{cm}^{2}$ and $31 \mu \mathrm{A} / \mathrm{cm}^{2}$ for high and low copper amalgam respectively. ${ }^{62}$ Johansson et al. ${ }^{68}$ studied the effect of surface treatments and electrode area size on the corrosion of cast and machined titanium in contact with conventional and high copper amalgams in saline solutions with and without fluoride ions. They found that conventional amalgam corroded more than high copper amalgams in contact with titanium in saline solutions. Also, surface preparations and fluorides effected the electrochemical activity of titanium. Increased level of titanium was released in tissue adjacent to titanium implants. ${ }^{69,70}$ Tissue reaction to released titanium varied from a mild to more severe inflammatory response. GeisGerstorfer et al. ${ }^{71}$ stated that the galvanic corrosion of implant/superstructure systems is important in two aspects: first, the possibility of biological effects that may result from the dissolution of alloy components and second, the current flow that results from galvanic corrosion may lead to bone destruction. Therefore, careful consideration is required when planning for an implant restoration so as to avoid the chances of galvanic corrosion.

\section{Effect of fluoride and Ph on titanium corrosion}

Various products like bleaching agents, mouth-rinses and toothpaste containing fluoride are popularly used for esthetic purposes and prevention of plaque and cavity formation. Carbamide peroxide and hydrogen peroxide $\left(\mathrm{H}_{2} \mathrm{O}_{2}\right)$ are most common ingredients in bleaching gels. ${ }^{72,73}$ Carbamide peroxide is used as a vehicle to transport $\mathrm{H}_{2} \mathrm{O}_{2}{ }^{73}$ Bleaching efficacy is influenced by concentration of bleaching gel and commercially available bleaching products range from $3 \%$ to $9.5 \%$ for hydrogen peroxide. ${ }^{72}$ Similarly, a high concentration of fluoride (ranging between 9000 and 19,000 ppm) exists in professionally applied fluoride products. ${ }^{72}$ Commonly used professionally applied fluoride products in dentistry include: (1) 1.23\% acidulated phosphate fluoride (APF) containing 12,300 ppm or $12.3 \mathrm{mg}$ of fluoride per $\mathrm{ml}$. The phosphoric acid present in the APF has a pH of approximately $3.5 ;(2) 2 \%$ sodium fluoride (NaF) and (3) $8 \%$ stannous fluoride $\left(\mathrm{SnF}_{2}\right) .{ }^{72}$ In the United States, $99 \%$ of the toothpastes marketed contain fluoride in concentrations between 1000 and 1500 ppm. According to the manufacturer, a treatment dose (a thin ribbon) of PreviDent ${ }^{\oplus}$ Brush-On Gel contains 2 mg fluoride.

Agents containing fluoride and hydrogen peroxide have been known to reduce corrosion resistance of $\mathrm{Ti}$ often resulting in visible discoloration around the implant. ${ }^{74}$ Studies have shown that fluorides can infiltrate the titanium oxide layer, especially at low pH levels. ${ }^{75,76}$ Siirila and Kononen in a study on topical fluoride effects of commercially pure titanium, concluded that toothbrushes that come in contact with titanium surfaces should be nonabrasive and should avoid long-lasting contamination with topical fluorides. ${ }^{77}$ In a study by Nakagawa et al. the corrosion behaviors of CpTi, Ti alloys (Ti-6Al$4 \mathrm{~V}$ and $\mathrm{Ti}-6 \mathrm{Al}-7 \mathrm{Nb}$ ) and new experimental alloys (Ti-Pt and $\mathrm{Ti}-\mathrm{Pd}$ ) were observed in a fluoride environment. The surfaces of new experimental alloys did not show any affect in acidic environment containing fluoride. However, the surfaces of the CpTi, Ti-6Al-4V alloy, and Ti-6Al-7Nb alloy showed significant evidence of surface roughness due to corrosion in similar conditions of low concentration of dissolved oxygen, low $\mathrm{pH}$ and a fluoride concentration similar to that present in the commercial dentifrices. $^{78}$ Low oxygen concentration makes the repair of damaged oxide layer due to corrosion difficult.

The corrosion process in titanium due to fluoride results in release of hydrogen as a reaction product, which in turn may cause delayed fracture due to hydrogen embrittlement. ${ }^{79}$ Kaneko et al. studied the 
hydrogen embrittlement titanium alloy in acid and neutral fluoride aqueous solutions. ${ }^{79}$ They concluded that the immersion in fluoride solutions leads to the degradation of the mechanical properties and fracture of titanium alloy. ${ }^{79}$ The corrosion resistance of titanium was lost in solution containing fluorides. ${ }^{23}$ Commercially pure titanium and titanium alloy cannot withstand exposure to NAF solution above a concentration level of $0.5 \% .^{74}$ Titanium was not considered to be corrosionresistant in a solution containing 500 ppm fluoride. ${ }^{80}$

Nakagawa et al. studied the effects of a combination of fluoride concentration and $\mathrm{pH}$ on the corrosion behavior of $\mathrm{Ti}^{81}{ }^{81}$ They found that $\mathrm{Ti}$ corroded at a critical $\mathrm{pH}$ and fluoride levels. The corrosion of $\mathrm{Ti}$ in the solution containing fluoride depended on the concentration of hydrofluoric acid (HF). According to their study the titanium corroded in acidic solution containing $\mathrm{NaF}$ in the ranges of $0.05-2 \%$.

Specifically, the corrosion resistance of titanium was lost in $0.01 \% \mathrm{NaF}$ solution ( $452.4 \mathrm{ppm}$ fluoride) at an acidic $\mathrm{pH}$ 4.2. At $\mathrm{pH}$ greater than 6.2, the corrosion resistance of Ti was maintained in a $2.0 \%, \mathrm{NaF}$ $(9048.8 \mathrm{ppm}$ F) solution. However, at pH less than 6.2, the titanium corroded in the same solution indicating that the protective oxide film of the titanium was destroyed in an acidic $\mathrm{pH}$ by the presence of fluoride ions. The corrosion of titanium is enhanced in an acidic environment, because $F$ ion in the solution combines with $\mathrm{H}^{+}$ion to form $\mathrm{HF}$, even if the NaF concentration is low. The result of this polarization test proved the calculated upper limit of HF concentration to be $21 \mathrm{ppm}$ where the corrosion resistance of titanium was maintained. When the HF concentration in the solution exceeded $30 \mathrm{ppm}$, the passivation film of the Ti was destroyed. ${ }^{81}$ Their finding was supported by the previous study by Lausmma et al. who reported that corrosion resistance of Ti was lost in a solution containing fluoride. ${ }^{23}$ Nakagawa et al. found that corrosion of titanium was not observed in the solution of $0.1 \%$ $\mathrm{NaF}$ (1000 ppm NaF) at pH 7.1, indicating that the passivation of titanium was not destroyed. ${ }^{81}$ Therefore, it proved that Ti corrosion did not occur if the $\mathrm{pH}$ value of the solution was neutral or higher than neutral. According to Probster et al. corrosion of titanium was often observed in prophylactic gels or solutions containing 400-9000 ppm fluoride because the $\mathrm{pH}$ of these gels and solutions was usually lower than neutral. ${ }^{24}$ Further reports based on studies done by Mimura and Miyagawa, stated that titanium was not considered to be corrosion resistant in the solution containing $500 \mathrm{ppm} \mathrm{F}$ at pH 4.80 Corrosion resistance of titanium was lost in the $0.1 \% \mathrm{NaF}(452.4 \mathrm{ppm} \mathrm{F})$ solution at $\mathrm{pH} 4.2 .{ }^{80}$ The results revealed a relation between the fluoride concentrations and $\mathrm{pH}$ values at which $\mathrm{Ti}$ corrosion occurred and provided data on such corrosion in environments where the fluoride concentration and $\mathrm{pH}$ value are known. ${ }^{80}$ Corrosion resistance of titanium is therefore controlled by the HF concentration and depended on the $\mathrm{pH}$ value and the total fluoride concentration in the solution. ${ }^{80}$

\section{Biologic reactions with titanium surface}

At present little is known about dental hypersensitivity to titanium implants. More long-term studies are warranted in order to better understand these reactions. Shibli et al. analyzed the surface topography and composition of failed titanium dental implants in order to determine possible causes of failure. ${ }^{82}$ Results from this study do not point at any material-related causes for implant failure. ${ }^{82} \mathrm{~A}$ study done on hypersensitivity to titanium has shown that none of the patients had any adverse reactions. ${ }^{83}$ Recent clinical reports however have shown patients showing symptoms of contact dermatitis or granulomatous reactions to titanium upon its use in pacemakers, ${ }^{84,85}$ hip prostheses, ${ }^{86}$ and even surgical clips. ${ }^{87}$ Additionally, the potential for adverse human tissue responses to titanium dioxide, the passivating layer that always covers the surface of titanium materials, has also been reported. ${ }^{88}$ Sensitivity to titanium is characterized by the local presence of abundant macrophages and 
T lymphocytes and by the absence of B lymphocytes, indicating Type 4 hypersensitivity. ${ }^{83}$ Type 4 hypersensitivity reaction is a cell-mediated, delayed response that occurs hours to days after exposure to the immunogen. It involves a complex series of steps that elicit a T-cell response to the antigen. Metals like nickel, cobalt and Ti are said to induce this type of reaction. Released Ti debris may combine with biomolecules to form a protein-metal complex and become immunogenic, eliciting a Tcell mediated Type 4 response. The typical manifestations of Type 4 hypersensitivity reactions include, but are not limited to unexplained pain, contact dermatitis, atopic eczema, impaired wound healing and sterile osteomyelitis. $^{89-91}$

Studies evaluating the oral tissue changes adjacent to titanium implants in patients reported no evidence of inflammatory response and no association between the identification of pigmented debris in the tissues and clinical symptoms. ${ }^{92}$ However, the relationship between titanium dental implants and clinically relevant hypersensitivity has been recently suggested. ${ }^{89}$ These reports raise the question that metal sensitivity may arise after exposure to titanium for some patients in certain circumstances. Report by Egusa et al. demonstrates the emergence of eczema localized to the perioperative facial area after receiving titanium dental implants, in which a complete remission was subsequently achieved by the removal of the titanium material. ${ }^{90}$ Thus it seems that titanium can induce hypersensitivity in susceptible patients and could play a critical role in implant failure. ${ }^{91}$ This validation needs long-term clinical and radiographic follow-up of all implant patients sensitive to metals.

\section{Surface modification of titanium and its effects on implant dentistry}

Over the years, several modifications to Ti have been experimented, tried and are no longer in use due to certain disadvantages, both clinically and biologically. Discussion of each of these methods in detail is beyond the scope of this review. However, among the many methods of titanium surface modification, some stand out and are promising for its future applications. One such surface modification is the electrochemical technique. This technique is both simple and cost effective and could be either anodic or cathodic in nature. Adjusting the anodic conditions like current density, voltage and solution concentration can alter porosity and surface roughness of Ti. By anodic oxidation desired chemical composition of the oxide layer can be achieved. In addition, anodic oxidation at high voltages can improve the crystalline structure of the oxide layer on the Ti surface resulting in superior properties of the oxide layer. ${ }^{93}$

Electrophoretic deposition is yet another method of Ti surface modification that uses hydroxyapatite (HA) powders dispersed in a suitable solvent at a particular $\mathrm{pH}$. These particles acquire positive charge in these conditions and coatings are obtained on the cathodic Ti by applying an external electric field. A post-sintering treatment is required to improve the coating properties. ${ }^{93}$ Electrophoretic HA coating on the Ti surface can either be obtained under constant or dynamic voltages. To improve the density of the electrophoretic coating it is usually sintered at a temperature of $600{ }^{\circ} \mathrm{C}$ or above. ${ }^{93}$ Another type of electrochemical method is cathodic deposition where HA is formed in situ from an electrolyte containing calcium and phosphate ions. This versatile process has control over electrophoretic coating thickness, crystallinity and substrate shape. ${ }^{93}$ Biocompatibility of Ti can further be improved by obtaining nano-size HA crystals. ${ }^{93}$ Lee et al. evaluated the surface characteristics and cell response of thermally treated Ti surfaces. ${ }^{94}$ They found that surface topography and crystalline structure changed with an increase in temperature due to phase transition of the oxide layer. The temperature increase resulted in enhanced oxygen solubility and a significant increase in the oxide layer thickness. With 
increase in temperature there was a decrease in contact angle and increase in surface energy thereby, increasing the wettability between the biological environment and the surface of the implant. Based on their study the authors concluded that the surface characteristics and biocompatibility of $\mathrm{Ti}$ increased as the temperature increased, indicating that surface modification by thermal treatment could be another useful method for modifying the surface of dental implants. ${ }^{94}$

Krupa et al. studied the effect of phosphorus ion implantation on corrosion resistance and biocompatibility of titanium implants. ${ }^{95}$ An increase in corrosion resistance of Ti implanted with phosphorous placed in simulated body fluid was observed after short-term and long-term exposure. The increased corrosion resistance was attributed to the alteration in the chemical composition and structure of the Ti surface layer following the implantation. Transmission electron microscopic examination of the microstructure revealed that after phosphorous ion implantation with a dose of $1 \times 10^{17} \mathrm{P}^{+} / \mathrm{cm}^{2}$, the surface layer of Ti became amorphous resulting in increased resistance to corrosion. According to the authors, another reason for increased corrosion resistance was the formation of TiP. ${ }^{95}$ The authors concluded that phosphorous ion implantation increases corrosion resistance of Ti by amorphisation of the Ti surface and by formation of TiP. They further added that at a dose of $1 \times 10^{17}$ $\mathrm{P}^{+} / \mathrm{cm}^{2}$ phosphorous ion implantation increased the corrosion resistance of Ti after short-term as well as long-term exposures. ${ }^{95}$

In another study by Park et al. titanium surfaces treated with $2 \% \mathrm{H}_{3} \mathrm{PO}_{4}$ showed increased tendencies in osteoblastic gene expression compared with those treated with lower $\mathrm{H}_{3} \mathrm{PO}_{4}$ concentrations or untreated surfaces. ${ }^{96}$ High concentration of $\mathrm{H}_{3} \mathrm{PO}_{4}$ treatment produced a homogenous crystalline phosphorous incorporated oxide layer with micro-rough surface topography that resulted in superior wettability of the Ti surface. The phosphorous incorporated Ti surfaces showed better osteoblast responses and significantly increased osseointegration of implants. These results demonstrate that $\mathrm{H}_{3} \mathrm{PO}_{4}$ treatment may improve the biocompatibility of Ti implants by improving differentiation, biomechanical anchorage and osteoblast attachment. ${ }^{96}$ These surface modifications appear to be promising in improving the future of titanium and its use in implant dentistry.

\section{Conclusion}

In conclusion, titanium and its alloys have a tremendous role in dentistry as well as in other fields of medicine. With increasing number of patients opting for implants as their choice of treatment for replacing missing teeth and restoring edentulous spaces, the importance of having a high performance material is critical. A vast body of research is being continually performed to upgrade the biological, mechanical and chemical properties of titanium for its optimal use as dental implants. However, of equal significance is the effect of the dynamic oral environment on this material. This review has covered several aspects of the oral environment and factors that can alter the longevity of titanium implants. Titanium implants are seldom used in isolation and are usually introduced into an oral environment where they face challenges with other metallic restorations, fluorides, bleaching chemicals and other agents. Clinicians should understand the effect of these factors while treatment planning and try to minimize the harmful interactions. Clearly, more research is needed in improving the success of titanium and its alloys for dental implant restoration. 


\section{Ethical approval}

No ethical approval and/or informed consent required.

\section{Conflict of interest}

The authors report no conflict of interest.

\section{Acknowledgments}

The authors would like to acknowledge Mr. Randall Gibson for his assistance in creating the figures for this review.

\section{References}

${ }^{1}$ Esposito M, Worthington H.V, Thomsen P, Coulthard P. "Interventions for replacing missing teeth: different types of dental implants." Cochrane Database Syst Rev 2003:CD003815.

${ }^{2}$ G. Hille. "Titanium for surgical implants." J Mater, 1 (1966), pp. 373-383.

${ }^{3}$ P.I. Brånemark. Introduction to osseointegration. P.I. Brånemark, T. Albrektsson (Eds.), Quintessence, Chicago (1985).

${ }^{4}$ R.R. Wang, A. Fenton. "Titanium for prosthodontic applications: a review of the literature." Quintessence Int, 27 (1996), pp. 401-408.

${ }^{5}$ E.P. Lautenschlager, P. Monaghan. "Titanium and titanium alloys as dental materials." Int Dent J, 43 (1993), pp. 245-253.

${ }^{6}$ R.R. Wang, A.M. Boyle. "A simple method for inspection of porosity in titanium castings." J Prosthet Dent, 70 (1993), pp. 275-276.

${ }^{7}$ M. Kononen, J. Rintanen, A. Waltimo, P. Kempainen. "Titanium framework removable partial denture used for patient allergic to other metals: a clinical report and literature review." J Prosthet Dent, 73 (1995), pp. 4-7.

${ }^{8} \mathrm{~J}$. Tormanen, O. Tervonen, A. Koivula, J. Junila, I. Suramo. "Image technique optimization in MR imaging of a titanium alloy joint prosthesis." J Magn Reson Imaging, 6 (1996), pp. 805-811.

${ }^{9}$ M. Roach. "Base metal alloys used for dental restorations and implants." Dent Clin North Am, 51 (2007), pp. 603-627. Vi.

${ }^{10}$ Y. Oshida. Introduction. Bioscience and bioengineering of titanium materials. Elsevier (2007), pp. 3-8. 1 st edition.

${ }^{11} \mathrm{~K}$. Wilhelm. Method for manufacturing titanium and alloys thereof. Google Patents (1940). 
${ }^{12}$ D.L. Cochran, R.K. Schenk, A. Lussi, F.L. Higginbottom, D. Buser. "Bone response to unloaded and loaded titanium implants with a sandblasted and acid-etched surface: a histometric study in the canine mandible." J Biomed Mater Res, 40 (1998), pp. 1-11.

13 J.A. Jansen, J.P. van de Waerden, J.G. Wolke, K. de Groot. "Histologic evaluation of the osseous adaptation to titanium and hydroxyapatite-coated titanium implants." J Biomed Mater Res, 25 (1991), pp. 973-989.

${ }^{14}$ J.A. Jansen, J.P. van der Waerden, J.G. Wolke. "Histological and histomorphometrical evaluation of the bone reaction to three different titanium alloy and hydroxyapatite coated implants." J Appl Biomater, 4 (1993), pp. 213-219.

${ }^{15}$ A. Palmquist, O.M. Omar, M. Esposito, J. Lausmaa, P. Thomsen. "Titanium oral implants: surface characteristics, interface biology and clinical outcome." J R Soc Interface, 7 (Suppl 5) (2010), pp. S515-S527.

${ }^{16}$ R. Branemark, L. Emanuelsson, A. Palmquist, P. Thomsen. "Bone response to laser-induced microand nano-size titanium surface features." Nanomedicine, 7 (2011), pp. 220-227.

${ }^{17}$ M. Esposito, H.V. Worthington, P. Coulthard. "Interventions for replacing missing teeth: dental implants in zygomatic bone for the rehabilitation of the severely deficient edentulous maxilla." Cochrane Database Syst Rev (2005), p. CD004151.

${ }^{18}$ M. Esposito, H.V. Worthington, P. Thomsen, P. Coulthard. "Interventions for replacing missing teeth: dental implants in zygomatic bone for the rehabilitation of the severely deficient edentulous maxilla." Cochrane Database Syst Rev (2003), p. CD004151.

${ }^{19}$ M. Esposito, H.V. Worthington, P. Coulthard, A. Jokstad. "Interventions for replacing missing teeth: maintaining and re-establishing healthy tissues around dental implants." Cochrane Database Syst Rev. (2002), p. CD003069.

${ }^{20}$ M. Esposito, H.V. Worthington, P. Coulthard, P. Thomsen. "Maintaining and re-establishing health around osseointegrated oral implants: a Cochrane systematic review comparing the efficacy of various treatments." Periodontol, 2003 (33) (2000), pp. 204-212.

${ }^{21}$ T. Albrektsson, A. Wennerberg. "Oral implant surfaces: Part 2 - review focusing on clinical knowledge of different surfaces." Int J Prosthodont, 17 (2004), pp. 544-564.

${ }^{22}$ N. Adya, M. Alam, T. Ravindranath, A. Mubeen, B. Saluja. "Corrosion in titanium dental implants: literature review." J Indian Prosthodont Soc, 5 (2005), pp. 126-131.

${ }^{23}$ J. Lausmaa, B. Kasemo, S. Hansson. "Accelerated oxide growth on titanium implants during autoclaving caused by fluorine contamination." Biomaterials, 6 (1985), pp. 23-27.

${ }^{24}$ L. Pröbster, W. Lin, H. Hüttemann. "Effect of fluoride prophylactic agents on titanium surfaces." Int J Oral Maxillofac Implants, 7 (1992), pp. 390-394. 
${ }^{25} \mathrm{H}$. Freese, M. Volas, J. Wood. "Metallurgy and technological properties of titanium and titanium alloys." DM TP Brunette, M. Textor (Eds.), Springer, Berlin (2001), pp. 25-53.

${ }^{26}$ D. Brown. "All you wanted to know about titanium, but were afraid to ask." Br Dent J, 182 (1997), pp. 393-394.

${ }^{27}$ K.J. Anusavice, R.W. Phillips. “Wrought alloys.” W.A. Brantley (Ed.) (11th ed), Saunders (2003), pp. 621-654.

${ }^{28}$ Y. Oshida. "Material classification. Bioscience and Bioengineering of titanium materials." (1st ed.), Elsevier (2007), pp. 9-22.

${ }^{29}$ N. Cabrera, N.F. Mott. "Theory of the oxidation of metals." Rep Prog Phys, 12 (1949), p. 163.

30 M.J. Donachie. "Titanium - a techincal guide." (2nd ed.), ASM International, Metals Park, OH (2000), pp. 123-130.

${ }^{31}$ M. McCracken. "Dental implant materials: commercially pure titanium and titanium alloys." J Prosthodont, 8 (1999), pp. 40-43.

${ }^{32}$ F.P. Fehlner, N.F. Mott. "Oxidation in the thin-film range. Oxidation of metals and alloys." American Society For Metals, Metals Park (1971), pp. 37-62.

${ }^{33}$ D. Jones. Principles and prevention of corrosion. (2nd ed.), Prentice Hall, New Jersey (1996).

${ }^{34}$ B. Kasemo, J. Lausmaa. "Aspects of surface physics on titanium implants." Swed Dent J Suppl, 28 (1985), pp. 19-36.

${ }^{35}$ B. Kasemo, J. Lausmaa. "Biomaterial and implant surfaces: a surface science approach." Int J Oral Maxillofac Implants, 3 (1988), pp. 247-259.

${ }^{36}$ B. Kasemo, J. Lausmaa. "Material-tissue interfaces: the role of surface properties and processes." Environ Health Perspect, 102 (Suppl 5) (1994), pp. 41-45.

${ }^{37}$ M. Pourbaix. "Electrochemical corrosion of metallic biomaterials." Biomaterials, 5 (1984), pp. $122-$ 134.

38 P. Tengvall, I. Lundstrom. "Physico-chemical considerations of titanium as a biomaterial." Clin Mater, 9 (1992), pp. 115-134.

39 "The glossary of prosthodontic terms." J Prosthet Dent, 94 (2005), pp. 10-92.

${ }^{40}$ H. Tschernitschek, L. Borchers, W. Geurtsen. "Nonalloyed titanium as a bioinert metal - a review." Quintessence Int, 36 (2005), pp. 523-530.

${ }^{41}$ L. Tang, J.W. Eaton. "Inflammatory responses to biomaterials." Am J Clin Pathol, 103 (1995), pp. 466471. 
42 "American Dental Association status report on the occurrence of galvanic corrosion in the mouth and its potential effects. Council on Dental Materials, Instruments, and Equipment." J Am Dent Assoc, 115 (1987), pp. 783-787.

${ }^{43}$ R.D. Meyer, J. Meyer, L.J. Taloumis. "Intraoral galvanic corrosion: literature review and case report." J Prosthet Dent, 69 (1993), pp. 141-143.

44 J. Karov, I. Hinberg. "Galvanic corrosion of selected dental alloys." J Oral Rehabil, 28 (2001), pp. 212219.

${ }^{45}$ V. Denaro, A. Cittadini, S.A. Barnaba, L. Ruzzini, L. Denaro, A. Rettino, B. De Paola, N. Papapietro, A. Sgambato. "Static electromagnetic fields generated by corrosion currents inhibit human osteoblast differentiation." Spine (Phila Pa 1976), 33 (2008), pp. 955-959.

${ }^{46}$ J.L. Gilbert, M. Mehta, B. Pinder. "Fretting crevice corrosion of stainless steel stem-CoCr femoral head connections: comparisons of materials, initial moisture, and offset length." J Biomed Mater Res B Appl Biomater, 88 (2009), pp. 162-173.

${ }^{47}$ C.H. Lohmann, Z. Schwartz, G. Koster, U. Jahn, G.H. Buchhorn, M.J. MacDougall, D. Casasola, Y. Liu, V.L. Sylvia, D.D. Dean, B.D. Boyan. "Phagocytosis of wear debris by osteoblasts affects differentiation and local factor production in a manner dependent on particle composition." Biomaterials, 21 (2000), pp. 551-561.

${ }^{48}$ A. Doran, F.C. Law, M.J. Allen, N. Rushton. "Neoplastic transformation of cells by soluble but not particulate forms of metals used in orthopaedic implants." Biomaterials, 19 (1998), pp. 751759.

${ }^{49}$ M.D. Rahal, D. Delorme, P.I. Branemark, D.G. Osmond. “Myelointegration of titanium implants: B lymphopoiesis and hemopoietic cell proliferation in mouse bone marrow exposed to titanium implants." Int J Oral Maxillofac Implants, 15 (2000), pp. 175-184.

${ }^{50}$ F. Contu, B. Elsener, H. Böhni. "A study of the potentials achieved during mechanical abrasion and the repassivation rate of titanium and Ti6Al4V in inorganic buffer solutions and bovine serum." Electrochimica Acta, 50 (2004), pp. 33-41.

${ }^{51}$ J.L. Gilbert, L. Zarka, E. Chang, C.H. Thomas. "The reduction half cell in biomaterials corrosion: oxygen diffusion profiles near and cell response to polarized titanium surfaces." J Biomed Mater Res, 42 (1998), pp. 321-330.

52 J.R. Goldberg, J.L. Gilbert. “In vitro corrosion testing of modular hip tapers." J Biomed Mater Res B Appl Biomater, 64 (2003), pp. 78-93.

${ }^{53}$ R. Venugopalan, J.J. Weimer, M.A. George, L.C. Lucas. "The effect of nitrogen diffusion hardening on the surface chemistry and scratch resistance of Ti-6Al-4V alloy." Biomaterials, 21 (2000), pp. 1669-1677. 
${ }^{54}$ M.T. Ehrensberger, J.L. Gilbert. "The effect of scanning electrical potential on the short-term impedance of commercially pure titanium in simulated biological conditions." J Biomed Mater Res, 94 (2010), pp. 781-789.

${ }^{55}$ M.T. Ehrensberger, J.L. Gilbert. "The effect of static applied potential on the $24 \mathrm{~h}$ impedance of commercially pure titanium in simulated biological conditions." J Biomed Mater Res- $B, 93$ (2010), pp. 106-112.

${ }^{56}$ M.T. Ehrensberger, S. Sivan, J.L. Gilbert. "Titanium is not "the most biocompatible metal" under cathodic potential: the relationship between voltage and MC3T3 preosteoblast behavior on electrically polarized cpTi surfaces." J Biomed Mater Res A, 93 (2010), pp. 1500-1509.

${ }^{57}$ M. Haeri, T. Wöllert, G.M. Langford, J.L. Gilbert. "Voltage-controlled cellular viability of preosteoblasts on polarized cpTi with varying surface oxide thickness." Bioelectrochemistry, 94 (2013), pp. 53-60.

${ }^{58}$ S. Sivan, S. Kaul, J.L. Gilbert. "The effect of cathodic electrochemical potential of Ti-6Al-4V on cell viability: voltage threshold and time dependence." J Biomed Mater Res B: Appl Biomater, 101 (2013), pp. 1489-1497.

${ }^{59}$ A.E. Charles, M.G. Ness. "Crevice corrosion of implants recovered after tibial plateau leveling osteotomy in dogs." Vet Surg, 35 (2006), pp. 438-444.

${ }^{60}$ A.C. Lewis, M.R. Kilburn, I. Papageorgiou, G.C. Allen, C.P. Case. "Effect of synovial fluid, phosphatebuffered saline solution, and water on the dissolution and corrosion properties of CoCrMo alloys as used in orthopedic implants." J Biomed Mater Res A, 73 (2005), pp. 456-467.

${ }^{61}$ N. Horasawa, S. Takahashi, M. Marek. "Galvanic interaction between titanium and gallium alloy or dental amalgam." Dent Mater, 15 (1999), pp. 318-322.

${ }^{62} \mathrm{G}$. Ravnholt, J. Jensen. "Corrosion investigation of two materials for implant supraconstructions coupled to a titanium implant." Scand J Dent Res, 99 (1991), pp. 181-186.

${ }^{63}$ T. Fusayama, T. Katayori, S. Nomoto. "Corrosion of gold and amalgam placed in contact with each other." J Dent Res, 42 (1963), pp. 1183-1197.

${ }^{64}$ L. Reclaru, R. Lerf, P.Y. Eschler, A. Blatter, J.M. Meyer. "Pitting, crevice and galvanic corrosion of REX stainless-steel/CoCr orthopedic implant material." Biomaterials, 23 (2002), pp. 3479-3485.

${ }^{65}$ R. Venugopalan, L.C. Lucas. "Evaluation of restorative and implant alloys galvanically coupled to titanium." Dent Mater, 14 (1998), pp. 165-172.

${ }^{66}$ H. Arslan, H. Celikkan, N. Ornek, O. Ozan, A.E. Ersoy, A.J. Aksu. "Galvanic corrosion of titanium-based dental implant materials." J Appl Electrochem, 38 (2008), pp. 853-859.

${ }^{67}$ G. Ravnholt. "Corrosion current and pH rise around titanium coupled to dental alloys." Scand J Dent Res, 96 (1988), pp. 466-472. 
${ }^{68}$ B.I. Johansson, B. Bergman. "Corrosion of titanium and amalgam couples: effect of fluoride, area size, surface preparation and fabrication procedures." Dent Mater, 11 (1995), pp. 41-46.

${ }^{69}$ G. Meachim, D.F. Williams. "Changes in nonosseous tissue adjacent to titanium implants." J Biomed Mater Res, 7 (1973), pp. 555-572.

${ }^{70}$ R.J. Solar, S.R. Pollack, E. Korostoff. "In vitro corrosion testing of titanium surgical implant alloys: an approach to understanding titanium release from implants." J Biomed Mater Res, 13 (1979), pp. 217-250.

${ }^{71}$ J. Geis-Gerstorfer, H. Weber, K.H. Sauer. "In vitro substance loss due to galvanic corrosion in Ti implant/Ni-Cr supraconstruction systems." Int J Oral Maxillofac Implants, 4 (1989), pp. 119123.

72 J.E. Dahl, U. Pallesen. "Tooth bleaching - a critical review of the biological aspects." Crit Rev Oral Biol Med, 14 (2003), pp. 292-304.

${ }^{73}$ G.R. Goldstein, L. Kiremidjian-Schumacher. "Bleaching: is it safe and effective?" J Prosthet Dent, 69 (1993), pp. 325-328.

${ }^{74}$ M. Nakagawa, S. Matsuya, K. Udoh. "Effects of fluoride and dissolved oxygen concentrations on the corrosion behavior of pure titanium and titanium alloys." Dent Mater J, 21 (2002), pp. 83-92.

${ }^{75}$ N. Ibris, J.C.M. Rosca. "EIS study of Ti and its alloys in biological media." J Electroanal Chem, 526 (2002), pp. 53-62.

${ }^{76} \mathrm{~B}$. Lindholm-Sethson, B.I. Ardlin. "Effects of $\mathrm{pH}$ and fluoride concentration on the corrosion of titanium." J Biomed Mater Res A, 86 (2008), pp. 149-159.

${ }^{77}$ H.S. Siirila, M. Kononen. "The effect of oral topical fluorides on the surface of commercially pure titanium." Int J Oral Maxillofac Implants, 6 (1991), pp. 50-54.

${ }^{78}$ M. Nakagawa, Y. Matono, S. Matsuya, K. Udoh, K. Ishikawa. "The effect of Pt and Pd alloying additions on the corrosion behavior of titanium in fluoride-containing environments." Biomaterials, 26 (2005), pp. 2239-2246.

${ }^{79}$ K. Kaneko, K. Yokoyama, K. Moriyama, K. Asaoka, J. Sakai, M. Nagumo. "Delayed fracture of beta titanium orthodontic wire in fluoride aqueous solutions." Biomaterials, 24 (2003), pp. 21132120.

${ }^{80} \mathrm{H}$. Mimura, Y. Miyagawa. "Electrochemical corrosion behavior of titanium castings: Part 1. Effects of degree of surface polishing and kind of solution." Jpn J Dent Mater Dev, 15 (1996), pp. 283-295.

${ }^{81}$ M. Nakagawa, S. Matsuya, T. Shiraishi, M. Ohta. "Effect of fluoride concentration and pH on corrosion behavior of titanium for dental use." J Dent Res, 78 (1999), pp. 1568-1572. 
82 J.A. Shibli, E. Marcantonio, S. d'Avila, A.C. Guastaldi, E. Marcantonio Jr. "Analysis of failed commercially pure titanium dental implants: a scanning electron microscopy and energydispersive spectrometer x-ray study." J Periodontol, 76 (2005), pp. 1092-1099.

${ }^{83}$ K.M. Holgers, G. Roupe, A. Tjellstrom, L.M. Bjursten. "Clinical, immunological and bacteriological evaluation of adverse reactions to skin-penetrating titanium implants in the head and neck region." Contact Dermat, 27 (1992), pp. 1-7.

${ }^{84}$ H.I. Abdallah, R.K. Balsara, A.C. O’Riordan. "Pacemaker contact sensitivity: clinical recognition and management." Ann Thorac Surg, 57 (1994), pp. 1017-1018.

85 J. Verbov. "Pacemaker contact sensitivity." Contact Dermat, 12 (1985), p. 173.

${ }^{86}$ P.A. Lalor, A.B. Gray, S. Wright, G.T. Railton, M.A. Freeman, P.A. Revell. "Contact sensitivity to titanium in a hip prosthesis?" Contact Dermat, 23 (1990), pp. 193-194.

${ }^{87}$ K. Tamai, M. Mitsumori, S. Fujishiro, M. Kokubo, N. Ooya, Y. Nagata, K. Sasai, M. Hiraoka, T. Inamoto. "A case of allergic reaction to surgical metal clips inserted for postoperative boost irradiation in a patient undergoing breast-conserving therapy." Breast Cancer, 8 (2001), pp. 90-92.

${ }^{88}$ C.A. Moran, F.G. Mullick, K.G. Ishak, F.B. Johnson, W.B. Hummer. "Identification of titanium in human tissues: probable role in pathologic processes." Hum Pathol, 22 (1991), pp. 450-454.

${ }^{89}$ K. Muller, E. Valentine-Thon. "Hypersensitivity to titanium: clinical and laboratory evidence." Neuro Endocrinol Lett, 27 (Suppl. 1) (2006), pp. S31-S35.

${ }^{90}$ H. Egusa, N. Ko, T. Shimazu, H. Yatani. "Suspected association of an allergic reaction with titanium dental implants: a clinical report." J Prosthet Dent, 100 (2008), pp. 344-347.

${ }^{91}$ A. Siddiqi, A.G. Payne, R.K. De Silva, W.J. Duncan. "Titanium allergy: could it affect dental implant integration?" Clin Oral Implants Res, 22 (2011), pp. 673-680.

${ }^{92}$ R.S. Flatebo, A.C. Johannessen, A.G. Gronningsaeter, O.E. Boe, N.R. Gjerdet, B. Grung, K.N. Leknes. "Host response to titanium dental implant placement evaluated in a human oral model." J Periodontol, 77 (2006), pp. 1201-1210.

${ }^{93}$ K.H. Kim, N. Ramaswamy. "Electrochemical surface modification of titanium in dentistry." Dent Mater J, 28 (2009), pp. 20-36.

${ }^{94}$ Y.J. Lee, D.Z. Cui, H.R. Jeon, H.J. Chung, Y.J. Park, O.S. Kim, Y.J. Kim. "Surface characteristics of thermally treated titanium surfaces." J Periodontal Implant Sci, 42 (2012), pp. 81-87.

${ }^{95}$ D. Krupa, J. Baszkiewicz, J.A. Kozubowski, A. Barcz, J.W. Sobczak, A. Bilinski, M. LewandowskaSzumiel, B. Rajchel. "Effect of phosphorus-ion implantation on the corrosion resistance and biocompatibility of titanium." Biomaterials, 23 (2002), pp. 3329-3340. 
${ }^{96}$ J.W. Park, Y.J. Kim, J.H. Jang, T.G. Kwon, Y.C. Bae, J.Y. Suh. "Effects of phosphoric acid treatment of titanium surfaces on surface properties, osteoblast response and removal of torque forces." Acta Biomater, 6 (2010), pp. 1661-1670. 